drug therapy in acute myocardial infarction: an overview of results from randomized controlled trials. JAMA 1993;270:1589-95.

68. Fitzgerald JD. By what means might beta blockers prolong life after acute myocardial infarction? Eur Heart J 1987;8:945-51.

69. Olsson G, Odèn A, Johansson L, Sjögren A, Rehnqvist N. Prognosis after withdrawal of chronic postinfarction metoprolol treatment: a $2-7$ year follow-up. Eur Heart J 1988;9:365-72.

70. Burris JF. $\beta$-blockers, dyslipidemia, and coronary artery disease: a reassessment. Arch Intern Med 1993;153:2085-92.

71. Byington RP, Worthy J, Craven T, Furberg CD. Propranolol-induced lipid changes and their prognostic significance after a myocardial infarction: the Beta-Blocker Heart Attack Trial experience. Am J Cardiol 1990;65:1287-91.

72. Adams MR, Clarkson TB, Koritnik DR, Nash HA. Contraceptive steroids and coronary artery atherosclerosis in cynomolgus macaques. Fertil Steril 1987;47:1010-8.

73. Blumlein SL, Sievers R, Kidd P, Parmley WW. Mechanism of protection from atherosclerosis by verapamil in the cholesterol-fed rabbit. Am $J$ Cardiol 1984;54:884-9.

74. Davignon J. Medical management of hyperlipidaemia and the role of probucol. Am J Cardiol 1986;57(suppl):22H-28H.

\title{
Angiotensin-converting enzyme inhibitors in patients with coronary atherosclerosis
}

\begin{abstract}
Activation of the renin-angiotensin-aldosterone system has been shown to be an independent risk factor for myocardial infarction (MI). The importance of this risk factor has been confirmed by the finding that patients with a DD genotype for the angiotensin-converting enzyme (ACE) gene, which is associated with increased serum ACE levels, have a higher incidence of MI than do patients without this genotype. ACE inhibitors have been shown to significantly reduce the incidence of recurrent $\mathrm{Ml}$ in patients with left ventricular dysfunction. The mechanism by which activation of the renin-anglotensin-aldosterone system leads to MI has not been ascertained, but it may be related to the effect of angiotensin II or aldosterone on the development of atherosclerosis, endothelial dysfunction, plaque rupture, or thrombosis after plaque rupture. Experimental data suggest that each of these mechanisms may be of importance. Several prospective randomized studies are under way to determine the effect of ACE inhibitors on recurrent ischemic events and the progression of atherosclerosis in patients without left ventricular dysfunction. If these studies yield positive results, ACE inhibitors might assume an important role in the secondary and possibly primary prevention of ischemic heart disease. (AM HEART J 1994;128:1328-32.)
\end{abstract}

Bertram Pitt, MD Ann Arbor, Mich.

The angiotensin-converting enzyme (ACE) inhibitors have been shown to be effective in reducing morbidity and mortality in patients with symptomatic and asymptomatic left ventricular (LV) dysfunction both in chronic heart failure and after myocardial infarction (MI). The results of several important trials-the Cooperative North Scandinavian Enalapril Survival Study (CONSENSUS I), ${ }^{1}$ the treatment and prevention arms of the Studies of Left Ventric-

From the Division of Cardiology, Department of Internal Medicine, University of Michigan Medical Center.

Reprint requests: Bertram Pitt, MD. Professor of Internal Medicine, University of Michigan Medical Center, 1500 E. Medical Center Dr., Ann Arbor, MI 48109.

Copyright 1994 by Mosby-Ycar Book, Inc. $0002-8703 / 94 / \$ 3.00+0 \quad \mathbf{4} / 0 / 60129$ ular Dysfunction (SOLVD), ${ }^{2,3}$ Survival After Left Ventricular Enlargement (SAVE), ${ }^{4}$ Acute Infarction Ramipril Efficacy (AIRE), ${ }^{5}$ CONSENSUS II, ${ }^{6}$ International Study of Infarct Survival (ISIS)-IV, ${ }^{7}$ and Gruppo Italiano per lo Studio della Sopravvivenza nell'Infarto Miocardico (GISSI)-III ${ }^{8}$-all suggest that patients with chronic LV dysfunction (ejection fraction $\leq 35 \%$ to $40 \%$ ), whether as a result of ischemic or nonischemic cardiomyopathy, and post-MI patients who have LV dysfunction, whether symptomatic or asymptomatic, can safely be treated with an ACE inhibitor unless contraindicated or not tolerated.

Results of several trials, in conjunction with recent experimental data, suggest that ACE inhibitors might have a role in the secondary and possibly primary prevention of coronary artery atherosclerosis and is- 
chemic heart disease. In both the SOLVD ${ }^{9}$ and $\mathrm{SAVE}^{4}$ trials, patients randomized to an ACE inhibitor-either enalapril (SOLVD) or captopril (SAVE) - had a significant reduction in the incidence of fatal or nonfatal MI on follow-up that averaged 40 and 42 months for SOLVD and SAVE, respectively. A relatively long lag time elapsed before the effect of ACE inhibitors on MI was noted, which is compatible with the hypothesis that the effect of ACE inhibitors on the occurrence of MI may be through an effect on atherosclerosis. By contrast, a reduction in MI incidence was not observed in the AIRE, ${ }^{5}$ ISIS-IV, 7 and GISSI-III ${ }^{8}$ trials in patients with acute MI. However, these trials had relatively short follow-up periods. An effect of ACE inhibitors on the development of coronary atherosclerosis, plaque rupture, or thrombosis after plaque rupture might require several years. The question of whether ACE inhibitors are effective in preventing coronary atherosclerosis and ischemic events in patients without $\mathrm{LV}$ dysfunction is being investigated in several prospective, randomized trials. Such patients were chosen for these trials to reduce the possibility that ACE inhibitors might demonstrate effectiveness in reducing the incidence of MI through their effects on preventing ventricular dilatation and to focus on the question of whether the renin-angiotensin-aldosterone system (RAAS) plays a significant role in the development of atherosclerosis and its manifestations. This article will briefly review the evidence for a role of the RAAS in atherogenesis and, consequently, whether ACE inhibition therapy has a role in the secondary prevention of ischemic heart disease.

\section{RAAS AND MI}

Support for a role of the RAAS in the pathogenesis of $\mathrm{MI}$ is derived from observational studies by Alderman et al. ${ }^{10}$ and genetic studies by Cambien et al. ${ }^{11}$ In an 8-year follow-up of patients with hypertension, Alderman et al. ${ }^{10}$ noted that an elevated serum renin level at baseline was an independent risk factor for MI, even after adjusting for smoking, hyperlipidemia, and diabetes mellitus. Although the results of this study demonstrated the importance of activation of the RAAS in the pathogenesis of MI, many clinicians remained skeptical, because activation of the RAAS may be due to diuretic usage and sodium intake, either of which might have been affected in a population with hypertension. However, the recent finding by Cambien et al. ${ }^{11}$ that patients with the DD form of the ACE genotype have a significantly increased incidence of MI has reemphasized the importance of the observations by Alderman et al. ${ }^{10}$ Patients with the DD ACE genotype have significantly higher plasma levels of ACE than do patients without this genotype. ${ }^{12}$ Because genotype is not affected by medication or sodium intake, these observations suggest that activation of the RAAS plays a fundamental role in the pathogenesis of MI. The initial observations of Cambien et al. ${ }^{11}$ have been supported by more recent reports that offspring of patients with the DD ACE genotype have a relatively high incidence of $\mathrm{MI}^{12}$ and a relatively increased incidence of heart transplantation. ${ }^{13}$

\section{POTENTIAL MECHANISMS BY WHICH ACE INHIBITORS MAY PREVENT MI}

Blood pressure lowering. The studies suggesting that activation of the RAAS is a new and independent risk factor for $M I$ raise questions as to the effectiveness of ACE inhibitors in preventing $\mathrm{MI}$ and, if so, the mechanism of this effect. One potential mechanism by which ACE inhibitors might prevent MI is through their effects on blood pressure.

Angiotensin II is a coronary and peripheral vasoconstrictor. ${ }^{14} \mathrm{ACE}$ inhibitors have been shown to be effective in the therapy of hypertension, and one could postulate that the proposed beneficial effects of ACE inhibitors in preventing MI could result from their effect in preventing coronary and peripheral vasoconstriction. However, in patients with coronary atherosclerosis and angina pectoris, ACE inhibitors have had a variable effect. In a study by Cleland et al., ${ }^{15}$ ACE inhibitor therapy resulted in increased incidence of angina pectoris, decreased exercise tolerance, and increased use of nitroglycerin. These adverse effects have been attributed to possible "coronary steal"; that is, the systemic and coronary vasodilatation induced by ACE inhibitors might divert coronary flow from collateral-dependent ischemic areas or the endocardium to nonischemic areas that supply collaterals to the myocardium or the epicardium, which has a greater coronary artery flow reserve than does the endocardium. The lack of short-term benefit in patients with angina pectoris demonstrated in the study by Cleland et al. does not eliminate the possibility that a long-term reduction in blood pressure by ACE inhibitors might be beneficial, because hypertension has been associated with an increased incidence of MI and endothelial dysfunction. However, a long-term reduction in blood pressure by other agents, such as $\beta$-adrenergic receptor blocking agents, has not proved as effective in preventing MI as might be predicted from their effects on blood pressure reduction. ${ }^{16}$ Therefore, whether the proposed effectiveness of ACE inhibitors in reducing $\mathrm{MI}$ is attributable at all or in part to their effects on blood pressure remains uncertain. 
Antiatherogenic effects. Independently of their effects on blood pressure, ACE inhibitors might have an important role in preventing atherosclerotic plaque formation, plaque rupture, or thrombosis after plaque rupture. Angiotensin II has been shown to stimulate various growth factors that might be important in the development of atherosclerosis, including platelet-derived growth factor. ${ }^{17}$ Angiotensin II has also been shown to stimulate the migration of neutrophils and macrophages into the vascular wall. ${ }^{18}$ Recently it was suggested that angiotensin II has an oxidant effect and increases the oxidation of LDL cholesterol ${ }^{19}$ and hence lipid uptake into the endothelium.

Patients with coronary artery narrowing as a result of atherosclerosis have evidence of endothelial dysfunction in the vessel with angiographic narrowing ${ }^{20}$ and in angiographically normal adjacent coronary arteries. ${ }^{21}$ Patients with multiple risk factors and angiographically normal coronary arteries have also been demonstrated to have endothelial dysfunction. ${ }^{22}$ Studies suggest that angiotensin II may be important in the development of endothelial dysfunction, which is believed to be a significant precursor to atherosclerosis. Animals fed an atherosclerotic diet develop endothelial dysfunction, as measured by loss of vasoconstrictor responses to acetylcholine and other endothelium-dependent vasodilators, whereas animals fed an identical diet plus an ACE inhibitor maintained normal endothelial function, with preserved vasodilator response to acetylcholine. ${ }^{23}$

ACE inhibitors may have an effect on the development of atherosclerosis per se by blocking the effects of angiotensin II. Experimental studies by Chobanian et al. ${ }^{24}$ show that animals fed an atherosclerotic diet develop pathologic evidence of atherosclerosis, whereas animals fed an identical diet plus an ACE inhibitor had significantly less evidence of vascular atherosclerosis.

Aldosterone and high-density lipoprotein cholesterol. Aldosterone has also been implicated in the development of atherosclerosis. There appears to be an inverse correlation between aldosterone levels and serum high-density lipoprotein (HDL) cholesterol levels. ${ }^{25} \mathrm{~A}$ reduction in serum HDL cholesterol levels would be expected to promote atherosclerosis. It has also been suggested that aldosterone is of importance in the development of endothelial dysfunction, in that patients with primary hyperaldosteronism have evidence of endothelial dysfunction that is reversed by removal of the aldosterone-producing tumor. ${ }^{26}$ It has been suggested that the occurrence of endothelial dysfunction in patients with primary hyperaldosteronism is independent of the effect of aldosterone on blood pressure. ${ }^{26}$ Thus by blocking the production of aldosterone and the conversion of angiotensin I to angiotensin II, ACE inhibitors might be effective in blocking the development of atherosclerosis through a reduction in HDL cholesterol, oxidation of LDL, prevention of endothelial dysfunction and atherosclerotic plaque formation.

Atherosclerotic plaque rupture. Angiotensin II might also contribute to the tendency for atherosclerotic plaques to rupture. Angiotensin II has been shown to cause the release of endothelin, an important mitogen and a potent coronary vasoconstrictor under certain circumstances, from the endothelium. ${ }^{27,28}$ The local release of endothelin could increase coronary vasoconstrictor tone in vascular areas with lipid-rich early atherosclerotic plaques and thereby cause plaque fissuring and rupture. Angiotensin II and aldosterone also cause the release of norepinephrine. ${ }^{29,30}$ Local release of norepinephrine might increase vasomotor tone and hence plaque rupture. ACE inhibitors, by preventing local endothelin or norepinephrine release, could help to prevent plaque rupture. Davies and Thomas ${ }^{31}$ and other investigators $^{32}$ have described the factors responsible for plaque rupture. ACE inhibitors might prevent plaque rupture by preventing the accumulation of lipid within the endothelium or by preventing a local increase in vasomotor tone.

Thrombosis after plaque rupture. In both experimental and clinical studies, ${ }^{33,34}$ angiotensin II has been shown to stimulate the release of plasminogen activator inhibitor. By preventing the release of plasminogen activator inhibitor, ACE inhibitors would increase the likelihood for spontaneous thrombolysis and prevention of thrombus formation. Evidence suggests that plaque rupture is relatively frequent but that complete thrombus formation after plaque rupture is relatively uncommon..$^{32}$ In most episodes of plaque rupture, platelet deposition and thrombosis formation are minimal or incomplete and lead to progression of the atherosclerotic lesion. In some instances, however, thrombus formation is more complete and leads to the clinical syndrome of unstable angina pectoris or, when complete without collateral development, to MI. ACE inhibitors could also prevent thrombus formation through their effect on preventing endothelial dysfunction and therefore platelet adhesion. Prevention of norepinephrine release by ACE inhibitors might also contribute to prevention of thrombus formation. Patients with heart failure, especially those treated with a loop diuretic, tend to have depletion of intracellular magnesium. ${ }^{35}$ ACE inhibitors and aldosterone tend to increase intracellular magnesium. Hypomagnesemia 
would tend to cause increased platelet aggregation and therefore thrombosis. Hypomagnesemia has also been suggested to be of importance in increasing coronary vasomotor tone and cytokine release. ${ }^{36}$

\section{CLINICAL TRIALS}

The observations regarding the RAAS by Alderman et al. ${ }^{10}$ and Cambien et al., ${ }^{11}$ the results of the $\mathrm{SOLVD}^{9}$ and $\mathrm{SAVE}^{4}$ studies, and the experimental evidence linking angiotensin II and aldosterone to endothelial function, ${ }^{20,26}$ atherosclerosis, ${ }^{33}$ and release of vasoactive substances ${ }^{27,30}$ have led to several prospective randomized trials evaluating the effect of $\mathrm{ACE}$ inhibitors in slowing or preventing atherosclerosis.

The Quinapril Ischemic Event Trial (QUIET) ${ }^{37}$ enrolled more than 1700 patients with normal LV function ( $\mathrm{LV}$ ejection fraction $>40 \%$ ) who had undergone percutaneous transluminal coronary angioplasty (PTCA) and who had at least one vessel outside the PTCA zone with minimal coronary artery disease. After a qualifying quantitative coronary angiogram, the patients were randomized to either placebo or ACE inhibitor (quinapril) therapy and will be followed up on for 3 years. The effect of quinapril on combined ischemic events, including cardiovascular death, MI, hospitalization for unstable angina pectoris, and the need for subsequent PTCA or coronary artery bypass graft will be determined. In a subset of 500 patients, the quantitative coronary angiogram will be repeated at the end of the 3-year period and the effect of quinapril on new coronary lesion formation and progression of coronary atherosclerosis will be determined. Randomization for the trial has been completed, and the final follow-up angiograms and patient follow-up will be completed by December 1996.

The Heart Outcomes Prevention Evaluation (HOPE) study (S. Yusuf, personal communication) uses a factorial design to examine the role of ACE inhibitor therapy (ramipril) and an antioxidant (vitamin E) on total mortality in 6000 patients with known coronary artery disease without heart failure. Patients with known coronary artery disease, including patients with diabetes mellitus, are being randomized to the ACE inhibitor or placebo and will be followed up on for 3 years. Several smaller ongoing trials with enalapril are also investigating the effect of $\mathrm{ACE}$ inhibition on the progression of coronary atherosclerosis.

Should these studies yield positive results and support the hypothesis that activation of the RAAS is an independent risk factor for MI, ACE inhibitors might assume an important role in the sec- ondary and, possibly, primary prevention of ischemic heart disease, especially in patients without hyperlipidemia.

\section{REFERENCES}

1. The CONSENSUS Trial Study Group. Effects of enalapril on mortality in severe congestive heart failure. N Engl I Med 1987;316:1429-35.

2. The SOLVD Investigators. Effect of enalapril on survival in patients with reduced left ventricular ejection fractions and congestive heart failure. N Engl J Med 1991;95:293-302.

3. The SOLVD Investigators. Effect of enalapril on mortality and the development of heart failure in asymptomatic patients with reduced left ventricular ejection fractions. N Engl J Med 1992;327:685-91.

4. Pfeffer MA, Braunwald E, Moye LA, Basta L, Brown EJ Jr, Cuddy TE, Davis BR, Geltman EM, Goldman S, Flaker GC, Klein M, Lamas GA, Packer M, Rouleau J, Rouleau JL, Rutherford J, Wertheimer JH, Hawkins CM, on behalf of the SAVE investigators. Effect of captopril on mortality and morbidity in patients with left ventricular dysfunction after acute myocardial infarction: results of the Survival and Ventricular Enlargement trial. N Engl J Med 1992;327:669-77.

5. The Acute Infarction Ramipril Efficacy (AIRE) Study Investigators. Effect of ramipril on mortality and morbidity of survivors of acute myocardial infarction with clinical evidence of heart failure. Lancet 1993;342:821-8.

6. Swedberg K, Held P, Kjekshus J, Rasmussen K, Ryden L, Wedel H, on behalf of the CONSENSUS II Study Group. Effects of the early administration of enalapril on mortality in patients with acute myocar. dial infarction: results of the Cooperative North Scandinavian Enalapril Survival Study II (CONSENSUS II). N Engl J Med 1992;327:678 84.

7. ISIS-IV Collaborative Group. ISIS-4 (Fourth International Study of Infarct Survival): randomized study of oral captopril in over 50,000 patients with suspected acute myocardial infarction [Abstract]. Circulation 1993;88:I394.

8. Gruppo Italiano per lo Studio della Sopravvivenza nell' Infarto Miocardico. GISSI-3: effects of lisinopril and transdermal glyceryl trinitrate singly and together on 6 -week mortalily and ventricular function after acute myocardial infarction. Lancet 1994;343:1115-22.

9. Yusuf S, Pepine CJ, Garces C, Pouleur H, Salem D, Kostis J, Benedict C, Rousseau M, Bourassa M, Pitt B. Effect of enalapril on myocardial infarction and unstable angina pectoris in patients with low ejection fractions. Lancet 1992;340:1173-8.

10. Alderman MH, Madhavan S, Ooi WL, Cohen H, Sealey JE, Laragh JA. Association of renin-sodium profile with risk of myocardial infarction in patients with hypertension. N Engl J Med 1991;324:1098-104.

11. Cambien F, Poirier O, Lecerf L, Evans A, Cambou J-P, Arveiler D, Luc G, Bard J-M, Bara L, Ricard S, Tiret L, Amouyel P, Alhenc-Gelas F, Soubrier F. Deletion polymorphism in the gene for angiotensinconverting enzyme is a potent risk factor for myocardial infarction. Nature 1992;359:641-4.

12. Tiret L, Kee F. Poirier O, Nicaud V, Lecerf L, Evans A, Cambou .J-P, Arveiler D, Luc G, Amouyel P, Cambien F. Deletion polymorphism in angiotensin-converting enzyme gene associated with parental history of myocardial infarction. Lancet 1993;341:991-2.

13. Raynolds MV, Bristow MR, Bush EW, Abraham WT, Lowes BD, Zisman LS, Taft CS, Perryman MB. Angiotensin converting enzyme DD genotype in patients with ischacmic or idiopathic cardiomyopathy. Lancet 1993;342:1073-5.

14. Nishimura H, Kubo S, Ueyama M, Kubota J, Kawamura K. Peripheral hemodynamic effects of captopril in patients with congestive heurt fuilure. AM HEART J 1989;117:100-5.

15. Cleland JGF, Henderson E, McLenachan J, Findlay IN, Dargie HJ. Effect of captopril, an angiotensin-converting enzyme inhibitor, in patients with angina pectoris and heart failure. Am Coll Cardiol 1991;17:733-9.

16. Collins R, Peto R, MacMahon S, Hebert P, Fiebach NH, Eberlein KA, Goodwin J, Qizilbash N, Taylor JO, Hennekens CH. Blood pressure, stroke, and coronary heart disease. Part 2, short-term reductions in blood pressure: overview of randomised drug trials in their epidemiological context. Lancet 1990;335:827-38. 
17. Naftilan AJ, Pratt RE, Eldridge CS, Lin HL, Dzau VJ. Angiotensin II induces $c$-fos expression in smooth muscle cell via transcriptional control. Hypertension 1989;13:706-11.

18. Farber HW, Center DM, Rounds S, Danilov SM. Components of the angiotensin system cause release of a neutrophil chemoattractant from cultured bovine and human endothelial cells. Eur Heart J 1990;11 (suppl B):100-7.

19. Keidar S, Brook JG, Aviram M. Angiotensin II enhanced lipid peroxidation of low-density lipoprotein. J Am Physiol Soc 1993;8:245-8.

20. Ludmer PL, Selwyn AP, Shook TL, Wayne RR, Mudge GH, Alexander RW, Ganz P. Paradoxical vasoconstriction induced by acetylcholine in atherosclerotic coronary arteries. N Engl J Med 1986;315:1046-51.

21. Werns SW, Walton JA, Hsia HH, Nabel EG, Sanz ML, Pitt B. Evidence of endothelial dysfunction in angiographically normal coronary arteries of patients with coronary artery disease. Circulation 1989;79:287-91.

22. Zeiher AM, Drexler H, Saurbier B, Just H. Effects of age, atherosclerosis, hypercholesterolemia, and hypertension: endothelium-mediated coronary blood flow modulation in humans. J Clin Invest 1993;92:65262.

23. Finta KM, Fischer MJ, Lee L, Gordon D, Pitt B, Webb RC. Ramipril prevents impaired endothelium-dependent relaxation in arteries from rabbits fed an atherogenic diet. Atherosclerosis 1993;100:149-56.

24. Chobanian AV, Haudenschild CC, Nickerson C, Drago R. Anti-atherogenic effect of captopril in the Watanabe heritable hyperlipidemic rabbit. Hypertension 1990;15:327-31.

25. Lind L, Lithell H, Wide L, Ljunghall S. Metabolic cardiovascular risk factors and the renin-aldosterone system in essential hypertension. $J$ Human Hypertens 1992;6:27-9.

26. Taddei S, Virdis A, Mattei P, Salvetti A. Vasodilation to acetylcholine in primary and secondary forms of human hypertension. Hypertension 1993;21:929-33.

27. Dohi Y, Hahn AWA, Boulanger CM, Buhler FR, Luscher TF. Endothelin stimulated by angiotensin II augments contractility of spontane- ously hypertensive rat resistance arteries. Hypertension 1992;19:131-7.

28. Hirata $Y$, Takagi $Y$, Fukuda $Y$, Marumo $F$. Endothelin is a potent mitogen for rat vascular smooth muscle cells. Atherosclerosis 1989;78:225-8.

29. Van Gilst WH, deGraeff PA, Wesseling H. Reduction of perfusion arrhythmias in the ischemic isolated rat heart by angiotensin converting enzyme inhibitors: a comparison of captopril, enalapril, and HOE 498. I Cardiovase Pharmacol 1986;8:722-8.

30. Barr CS, Hanson J, Kennedy N, Lang CC, Struthers AD. The effect of a mineralocorticoid antagonist on myocardial mIBG uptake in congestive heart failure [Abstract]. Circulation 1993;88:1256.

31. Davies MJ, Thomas AC. Plaque fissuring: the cause of acute myocardial infarction, sudden ischaemic death, and crescendo angina. Br Heart $J$ $1985 ; 53: 363-73$.

32. Fuster V, Badimon L, Badimon JJ, Chesebro JH. The pathogenesis of coronary artery disease and the acute coronary syndromes. N Engl J Med 1992;326:242-50, 310-8.

33. Rydzewski B, Zelezna B, Tang W, Sumners C, Raizada MK. Angiotensin II stimulation of plasminogen activator inhibitor-1 gene expression in astogial cells from the brain. Endocrinology 1992;130:1255-62.

34. Ridker PRM, Gaboury CL, Conlin PR, Seely EW, Williams GH, Vaughan DE. Stimulation of plasminogen activator inhibitor in vivo by infusion of angiotensin II: evidence of a potential interaction between the renin-angiotensin system and fibrinolytic function. Circulation 1993;87:1969-73

35. Wester PO, Dyckner' $T$. Intracellular electrolytes in cardiac failure. Acta Med Scand 1986;707:33-6.

36. Weglicki WB, Phillips TM, Freedman AM, Cassidy MM, Dickens BF. Magnesium-deficiency elevates circulating levels of inflammatory cytokines and endothelin. Mol Cell Biochem 1992;110:169-73.

37. Texter M, Lees RS, Pitt B, Dinsmore KE', Uprichard ACG. 'The QUinapril Ischemic Event Trial (QUIET) design and methods: evaluation of chronic ACE inhibitor therapy after coronary artery interven. tion. Cardiovasc Drugs Ther 1993;7:273-82. 